\title{
IN SITU, TIME-RESOLVED RAMAN SPECTROMICROTOPOGRAPHY OF AN OPERATING LITHIUM ION BATTERY
}

\author{
Yu Luo, Wen-Bin Cai, Xue-kun Xing and Daniel A. Scherson \\ Department of Chemistry \\ Case Western Reserve University \\ Cleveland, OH 44106-7078
}

\begin{abstract}
A Raman microscope has been coupled to a computer-controlled, two-dimensional linear translator attached to a custom-designed, sealed optical chamber to allow in situ acquisition of space-, and time-resolved spectra of an operating thin graphite/ $/ \mathrm{LiCO}_{2} \mathrm{Li}$-ion battery. This unique arrangement made it possible to collect continuously series of Raman spectra from a sharply defined edge of the battery exposing the anode $(\mathcal{A})$, separator $(\mathcal{S})$, and cathode $(\mathcal{C})$, during charge and discharge, while the device was moved back and forth under the fixed focused laser beam along an axis normal to the layered $\mathcal{A}|\mathcal{S}| \mathcal{C}$ plane. Clear spectral evidence was obtained for changes in the amount of $\mathrm{Li}^{+}$within particles of graphite in the anode, and, to a lesser extent, of $\mathrm{LiCoO}_{2}$ in the cathode, during battery discharge both as a function of position and time. Analysis of time-resolved Raman spectromicrotopography (SMT) measurements of the type described in this work are expected to open new prospects for assessing the validity of theoretical models aimed at simulating the flow of $\mathrm{Li}^{+}$within $\mathrm{Li}$-ion batteries under operating conditions.
\end{abstract}

\section{INTRODUCTION}

Over the past few years, attention has been focused in this ${ }^{1-5}$ and other ${ }^{6-14}$ laboratories toward application of Raman spectroscopy as an in situ vibrational probe of electrode materials of relevance to electrochemical energy storage. These efforts culminated recently in the first acquisition of in situ Raman spectra from a technical gel-type $\mathrm{Zn}$ anode in a genuine alkaline battery environment during 
high current discharge ${ }^{15}$ For these experiments, a hole was cut into the positive end of a commercial AA $\mathrm{Zn} / \mathrm{MnO}_{2}$ battery and replaced by a thin optical window attached to its outer casing using epoxy resin. This configuration allowed Raman spectra of the $\mathrm{Zn}$ powder electrode to be collected from a single spot on the $\mathrm{Zn}$ powder anode during discharge, while preserving both the mechanical integrity of the battery, as well as its expected electrochemical response, i.e. discharge time to $1.0 \mathrm{~V}$ at $1 \mathrm{~A}$ of ca. $30-35 \mathrm{~min}$.

This work presents in situ, space-, and time-resolved Raman measurements of electrodes in an operating Li-ion battery during discharge. Key to the success of this time-resolved spectromicrotopography (SMT) technique was the coupling of a Raman microscope to a computercontrolled two-dimensional linear translator, as well as the use of an environmental chamber to prevent contact of the battery with the ambient atmosphere. This arrangement enabled Raman spectra to be collected continuously from a sharply defined edge of the battery exposing the anode, separator and cathode, during charge and discharge, while the device was being displaced back and forth under the fixed focused laser beam along an axis normal to the layered edge plane. The ultimate objective of this methodology is to obtain information that will allow a more detailed assessment of the extent of validity of current theoretical models aimed at simulating the flow of $\mathrm{Li}^{+}$within $\mathrm{Li}$-ion batteries during charge and discharge, and provide rational bases for achieving improved performance.

\section{EXPERIMENTAL}

\section{Ex situ Battery Characterization and Activation}

The thin Li-ion battery ( $4 \mathrm{~mm}$ width, $20 \mathrm{~mm}$ height, ca. $0.5 \mathrm{~mm}$ thickness) examined in this work incorporates a carbon anode $\left(\mathcal{A}, 120 \sim 140 \mu \mathrm{m}\right.$ thick), a separator $(\mathcal{S}, 32 \sim 34 \mu \mathrm{m})$, and a $\mathrm{LiCoO}_{2}$ cathode $(\mathcal{C},>300 \mu \mathrm{m}$ thick) with copper (for $\mathcal{A}$ ) and aluminum (for $\mathcal{C}$ ) meshes as current collectors $(\mathfrak{c c}$ ). A schematic diagram of this device (not including the anode current collector) is shown on the left side, Panel A, Fig. 1, where relative dimensions have been altered for clarity. Prior to the acquisition of in situ 
time-resolved Raman spectromicrotopography (SMT) measurements, a sharp razor was used to cut the battery to about a quarter of its original size, i.e. $20 \times 15 \mathrm{~mm}$, exposing a sharply defined $\mathcal{A}|\mathcal{S}| \mathcal{C}$ stratified edge. A non-spectroscopic image of a section of this edge recorded with the Raman microscope attachment (see Panel C, Fig. 1) revealed roughly circular particles of graphite $(20 \sim 24 \mu \mathrm{m}$ in diameter) in the anode, $\mathcal{A}$, and of $\mathrm{LiCoO}_{2}$ (ca. $4 \mu \mathrm{m}$ in diameter) in the cathode, $C$.

Raman spectra obtained by focusing the laser beam (see grey circle in $\mathcal{A}$, right panel, Fig. 2 , for approximate dimensions) onto individual particles along the battery edge yielded features characteristic of graphite $\left(1580\right.$ and $\left.1350 \mathrm{~cm}^{-1}\right)$ and $\mathrm{LiCoO}_{2}\left(484\right.$ and $\left.595 \mathrm{~cm}^{-1}\right)$ in the anode (lower curve, left panel) and cathode (upper curve in the same panel), respectively, with very small contributions due to the high area carbon used as a conductivity enhancer (1375 and $1600 \mathrm{~cm}^{-1}$, see lower curve, left Panel, Fig. 2). Also shown in this figure (see middle trace, left panel) is the corresponding spectrum of the dry separator, $\mathcal{S}$.

The battery was then transferred to a high quality glove box (Vacuum Atmospheres), heated under reduced pressure in an internal vacuum oven (first at $54^{\circ} \mathrm{C}$ for $6 \mathrm{~h}$, and then at $27^{\circ} \mathrm{C}$ for $15 \mathrm{~h}$ ) to desorb water within the structure, and subsequently soaked for $30 \mathrm{~min}$ in $1 \mathrm{M} \mathrm{LiPF} 6$ in EC/DMC (2:1 w/w) electrolyte solution. After removing excess electrolyte with absorbent paper, two flat Au foils (see right section, Panel B, Fig. 1) were pressed against the metal meshes ( $c c)$ on each side of the battery followed by two identical polypropylene (PP) hemicylindrical sections. This assembly was then inserted into a cylindrical cavity bore along the main axis of a solid cylindrical PP cell, as shown schematically in the right section, Panel A, Fig. 1. An optically transparent sapphire window (thickness: $0.5 \mathrm{~mm}$; diameter: $28.58 \mathrm{~mm}$ ) placed onto an O-ring set on an annular groove machined on the flat end of the PP cylinder, and compressed using a set of bolts, was used to isolate the battery from the ambient 
atmosphere during the Raman SMT measurements (see left section, Panel B, Fig. 1). Electronic contact with the battery electrodes was achieved by pressing stainless steel foils against the Au foils outside the hemicylinders, using small bolts inserted through under-sized orifices drilled manually into the PP cell as feedthroughs (see right section of Panel B in this figure). The spectroelectro-chemical cell was then removed from the glovebox and mounted onto a computer controlled, variable-speed, two-dimensional linear actuator (Newport, Model $850-1$ ) driven by a $855 \mathrm{C}$ Programmable Controller with a digital coordinate display. Subsequently, the entire assembly was attached to a manual translator to allow the distance between the microscope objective and the battery XY plane, i.e. along the Z-axis (see left section, Panel A, Fig. 1), and thus focus the beam on the cut edge of the battery during Raman spectromicrotopography (SMT) analysis. Other experimental details are given in subsections to follow.

\section{Electrochemistry}

The battery was charged and discharged at a constant current of $0.2 \mathrm{~mA}$, using a Pine potentiostat (AFRDE 5) operating in the galvanostatic mode.

\section{In situ, Space-, and Time-resolved Raman Spectromicrotopography (SMT)}

Raman spectra were collected from the cut-edge (XY) plane of the battery in the $180^{\circ}$ back scattering configuration (see Panels A and B, Fig. 1, where the darker vertical line represents the incident laser beam, and the shaded lighter area the scattered beam collected by the microscope objective) with a Chromex Raman 2000 system equipped with a $20 \mathrm{X}$ Olympus microscope described in earlier publications, ${ }^{1,3}$ while charging and discharging the battery. A Verdi 10 laser $(\lambda=532 \mathrm{~nm}$, Coherent Inc.) was used as the excitation source at powers on the sample on the order of $8 \mathrm{~mW}$. The integration time for each spectrum was $15 \mathrm{~s}$. A set of 30 spatially averaged Raman spectra were taken without interruption while the battery moved at a speed of $0.4 \mu \mathrm{m} / \mathrm{s}$ over a distance of $180 \mu \mathrm{m}$ under the focused laser beam exposing sections of the anode, the entire separator region, and sections of the 
cathode during charge and discharge; hence, each spectrum represents a spatial average over a $6 \mu \mathrm{m}$ linear region. Once the prescribed end along the $\mathrm{x}$-axis was reached, the scan was interrupted for $20 \mathrm{~s}$ while collecting spectra, and subsequently resumed in the reverse direction until the battery returned to its original position. The ability of the translator to achieve a prescribed coordinate following movement was verified by comparing the spectral response.

\section{RESULTS AND DISCUSSION}

Shown in Fig. 3 from top to bottom is a series of 30 spatially averaged $(6 \mu \mathrm{m})$ in situ Raman spectra obtained in sequence along the $\mathrm{x}$-axis close to the center of the battery (see Panel C, Fig. 1) divided into regions comprising mostly the anode $(\mathcal{A}$, Panel $\mathrm{A}$, ca. $78 \mu \mathrm{m})$ the separator $(\mathcal{S}$, Panel B, ca. $30 \mu \mathrm{m})$ and the cathode $(C$, Panel C, ca. $42 \mu \mathrm{m})$ in the fully discharged state. Although clearly visible in the ex situ non-spectroscopic image of the edge (see right panel, Fig. 2), no individual cathode or anode particles could be identified in corresponding images recorded in situ (not shown in this figure) due to a loss in effective resolution caused by the sapphire window. Nevertheless, cursory inspection of the Raman data in Panel A, Fig. 3, where the arrow points in a direction toward the separator, revealed spatially-resolved spectral features attributed to graphite, ${ }^{2,14}$ i.e. $t_{2 \mathrm{~g} 2}(\mathrm{G})$ and $\mathrm{D}$ bands at 1580 and 1350 $\mathrm{cm}^{-1}$ (see Panel A, Fig. 3), respectively, and a sharp and a broad feature centered at ca. $1375 \mathrm{~cm}^{-1}$ and ca. $1600 \mathrm{~cm}^{-1}$ attributed to the high area carbon used as a conductivity enhancer. Statistical analysis of these data allowed for line images of the electrode edge to be constructed based solely on the intensity of the spectral signatures, from which the position of the graphite particles along the line scan could be easily inferred (see grey scale on the right hand side of Panel A in this figure).

A similar behavior was found for similar SMT Raman scans over the cathode (see Panel C, Fig. 3), where the local increase in the magnitudes of the 484 and $595 \mathrm{~cm}^{-1}$ features, ${ }^{12,13}$ ascribed to the $\mathrm{E}_{\mathrm{g}}$ 
and $\mathrm{A}_{1 \mathrm{~g}}$ modes of $\mathrm{LiCoO}_{2}$, is attributed to the presence of particles of this material on the cut edge of the battery. The arrow in this case points in a direction away from the separator. Because of the much less defined spectral features, no attempt was made to generate a grey scale image for $\mathrm{LiCoO}_{2}$ in this electrode. Also shown for completeness in Panel B in this figure is a series of virtually identical SMT Raman spectra recorded over the entire width of the separator, where all features, except those indicated by the arrows (see also middle curve in the left Panel, Fig. 2), are due to the electrolyte.

These results afford clear evidence that in situ Raman microscopy can be used to probe small regions, including individual particles for the anode, within technical electrodes in a genuine Li-ion battery environment.

In a second series of experiments, time-resolved, Raman SMT measurements were performed in situ while the battery was first charged at $0.2 \mathrm{~mA}(\mathrm{C} / 20)$ for $9 \mathrm{~h}$, then disconnected for ca. 1 hour (OC in Fig. 4), and subsequently discharged at $-0.2 \mathrm{~mA}$ for ca. $6 \mathrm{~h}$, yielding a voltage vs. time plot shown in Fig. 4. During this entire period of time, the battery was continuously translated under the focused laser beam over a range of $180 \mu \mathrm{m}$ and spectra were collected without interruption. Shown in Fig. 5 are timeresolved spectra recorded during battery discharge at three different positions within the anode, $\mathrm{x}=6$ (Panel A), 30 (Panel B) and $60 \mu \mathrm{m}$ (Panel C) where x represents the distance from the separator. Corresponding data collected for the cathode at $\mathrm{x}=6 \mu \mathrm{m}$ (Panel A) 24 (Panel B) and $48 \mu \mathrm{m}$ (Panel C) are given in Fig. 6. A number of interesting conclusions can be drawn from a cursory examination of these plots. In particular, the rate at which the intensity of the bands ascribed to the electrochemically active materials in their discharged form increases is faster for areas of the electrodes closer to the separator (provided, of course, those areas do contain active material), as would be expected based on simple resistance considerations. Furthermore, large increases in the intensity of the $t_{2 \mathrm{~g} 2}(\mathrm{G})$ and D bands at $1580 \mathrm{~cm}^{-1}$ and $1350 \mathrm{~cm}^{-1}$, consistent with in situ Raman data obtained for embedded graphite 
particles in $\mathrm{Ni}$ foils during discharge, ${ }^{2,3}$ were observed when the beam was focused directly on a graphite particle at $\mathrm{x}=30 \mu \mathrm{m}$ over the first $120-135 \mathrm{~min}$ (Panel B), and to a lesser extent at $60 \mu \mathrm{m}$ away from the separator (Panel C) during during the first $195 \mathrm{~min}$.

Semiquantitative time-, and space-resolved information regarding the state of charge of graphite particles within the anode during battery discharge could be obtained by fitting each of the curves in Fig. 5 to sets of two Lorentzians. The quality of the spectral deconvolutions is illustrated in Fig. 7 for three of these curves. Based on this analysis, values of the integrated intensity of the Raman band component at $1580 \mathrm{~cm}^{-1}$, i.e. II(1580), at a specific distance, were then plotted as a function of time (see Fig. 8), where the lines are arbitrary fits to the experimental points. As indicated therein, the graphite signal at a distance $6 \mu \mathrm{m}$ away from the separator reached its maximum after the battery was discharged for 15 min. As expected, the rate at which the signals were found to vary decreased, as the distance from the separator increased.

In the case of the cathode, the increase in the magnitudes of the $\mathrm{LiCoO}_{2}$ bands at 483 and 593 $\mathrm{cm}^{-1}, \mathrm{I}\left(\mathrm{LiCoO}_{2}\right)$, for measurements made $6 \mu \mathrm{m}$ away from the separator (see Panel A, Fig. 6), was rather modest, and appeared to occur over very short periods of time, ca. $<15 \mathrm{~min}$. In contrast, steady increases in $\mathrm{I}\left(\mathrm{LiCoO}_{2}\right)$ could be clearly discerned at $\mathrm{x}=24 \mu \mathrm{m}$ for times up to 75 to 105 min, whereas farther away from the separator, i.e. $48 \mu \mathrm{m}$, such changes could be reliably detected only at about 210 min (see Panel C, Fig. 6).

Although largely qualitative at this stage of development, in situ Raman spectromicrotography (SMT) could be used to construct time-resolved, two-dimensional spatial maps of the state of charge within the electrodes, which can be assembled to generate dynamic images of $\mathrm{Li}^{+}$transport within the entire battery, for which the time resolution will be primarily determined by the rate of spectral 
acquisition. This overall strategy will also enable time-resolved SMT images to be collected for various modes of charge and discharge including constant current, constant potential and constant power, as well as monitor relaxation dynamics for both intermittent charge and discharge modes. Efforts in this direction are currently underway and will be reported in due course.

\section{ACKNOWLEDGEMENTS}

This work was supported in part by NASA-Glenn and the US Department of Energy, Office of Basic Energy Sciences.

\section{REFERENCES}

(1) Luo, Y.; Cai, W.-B.; Scherson, D. A. Electrochemical and Solid State Letters 2001, 4, A101A104.

(2) Totir, D. A.; Scherson, D. A. Electrochemical and Solid State Letters 2000, 3, 263-265.

(3) Luo, Y.; Cai, W. B.; Scherson, D. A. J. Electrochem. Soc. 2002, 149, A1100-A1105.

(4) Mo, Y. B.; Stefan, I. C.; Cai, W. B.; Dong, J.; Carey, P.; Scherson, D. A. J. Phys. Chem. B 2002, $106,3681-3686$.

(5) Mo, Y. B.; Cai, W. B.; Dong, J. A.; Carey, P. R.; Scherson, D. A. Electrochemical and Solid State Letters 2001, 4, E37-E38.

(6) Desilvestro, J.; Corrigan, D. A.; Weaver, M. J. J. Phys. Chem. 1986, 90, 6408-6411.

(7) Desilvestro, J.; Corrigan, D. A.; Weaver, M. J. J. Electrochem. Soc. 1988, 135, 885-892.

(8) Oblonsky, L. J.; Devine, T. M. J. Electrochem. Soc. 1995, 142, 3677.

(9) Melendres, C. A.; Pankuch, M. J. Electroanal. Chem. 1992, 333, 103.

(10) Kostecki, R.; McLarnon, F. J. Electrochem. Soc. 1997, 144, 485.

(11) Hugot-Le Goff, A.; Joiret, S.; Saidani, B.; Wiart, R. Journal of Electroanalytical Chemistry $1989,263,127$. 
(12) Itoh, T.; Sato, H.; Nishina, T.; Matue, T.; Uchida, I. J. Power Sources 1997, 68, 333-337.

(13) Inaba, M.; Iriyama, Y.; Ogumi, Z.; Todzuka, Y.; Tasaka, A. J. Raman Spectrosc. 1997, 28, 613617.

(14) Inaba, M.; Yoshida, H.; Ogumi, Z.; Abe, T.; Mizutani, Y.; Asano, M. J. Electrochem. Soc. 1995, 142, 20-26.

(15) Cai, W. B.; Shi, Q. F.; Mansuetto, M. F.; Scherson, D. A. Electrochemical and Solid State Letters 2000, 3, 319-320.

\section{FIGURE CAPTIONS}

Fig. 1. Schematic diagram of the battery (Panel A) and spectroelectrochemical cell (Panel B), and microscopic image of a sharp edge of the battery showing the carbon anode $(\mathcal{A}, 120 \sim 140 \mu \mathrm{m}$ thick), the separator $(S, 32 \sim 34 \mu \mathrm{m})$, and the $\mathrm{LiCoO}_{2}$ cathode $(C,>300 \mu \mathrm{m}$ thick) and the current collectors meshes $(c c)$, i.e. copper (for $\mathcal{A}$ ) and aluminum (for $\mathcal{C}$, not shown) (Panel C). Raman spectra were collected along the $\mathrm{x}$-axis in the direction indicated.

Fig. 2. Right Panel. Image obtained with the microscope attachment of the Raman 2000 showing the layered structure of the Li-ion battery. Left Panel: Raman spectra of random regions of the cathode, $\mathcal{C}$, separator, $\mathcal{S}$, and anode, $\mathcal{A}$. Laser excitation wavelength: $532 \mathrm{~nm}$. The grey circle in the picture represents the laser beam image on the battery (see text for other details).

Fig. 3. Series of 30 spatially-averaged $(6 \mu \mathrm{m})$ in situ Raman spectra collected in sequence along the $\mathrm{x}-$ axis close to the center of the battery (see Panel C, Fig. 1) within the anode (Panel A, ca. $78 \mu \mathrm{m}$ ) separator (Panel B, ca. $30 \mu \mathrm{m}$ ) and cathode regions (Panel C, ca. $42 \mu \mathrm{m}$ ) for the battery in the fully discharged state 
Fig. 4. Voltage vs time profile during galvanostatic charge and discharge of the lithium battery at a constant current of $+0.2 \mathrm{~mA}$ and $-0.2 \mathrm{~mA}$, respectively (allowing the battery to relax (OC) for about one hour in between), while acquiring time-, and spatially-resolved Raman spectra as specified in the text.

Fig. 5. Series of Raman spectra taken at the same spot on the anode during battery discharge at 6 (Panel A), 30 (Panel B) and $60 \mu \mathrm{m}$ (Panel C) from the separator as a function of time (see values next to
the right axis).

Fig. 6. Series of Raman spectra taken at the same spot on the cathode during battery discharge at 6 (Panel A), 24 (Panel B) and $48 \mu \mathrm{m}$ (Panel C) from the separator as a function of time (see values next to the right axis).

Fig. 7. Statistical fits in terms of two Lorentzians of three Raman spectra selected from the larger set shown in Fig. 5, namely, $t=45 \min$ and $x=60 \mu \mathrm{m}($ Panel $A) ; t=196 \min$ and $x=6 \mu m($ Panel $\mathrm{B})$, and $\mathrm{t}=180 \mathrm{~min}$ and $\mathrm{x}=30 \mu \mathrm{m}($ Panel $\mathrm{C})$.

Fig. 8. Plots of the integrated intensity of the graphite band at $1580 \mathrm{~cm}^{-1}$, II(1580), for the anode region along the battery edge, derived from the statistical analysis of the data shown in Fig. 5, at specific points $\mathrm{x}$ from the separator, as a function of time during galvanostatic discharge (see Fig. 4). The lines represent arbitrary fits to the data. 


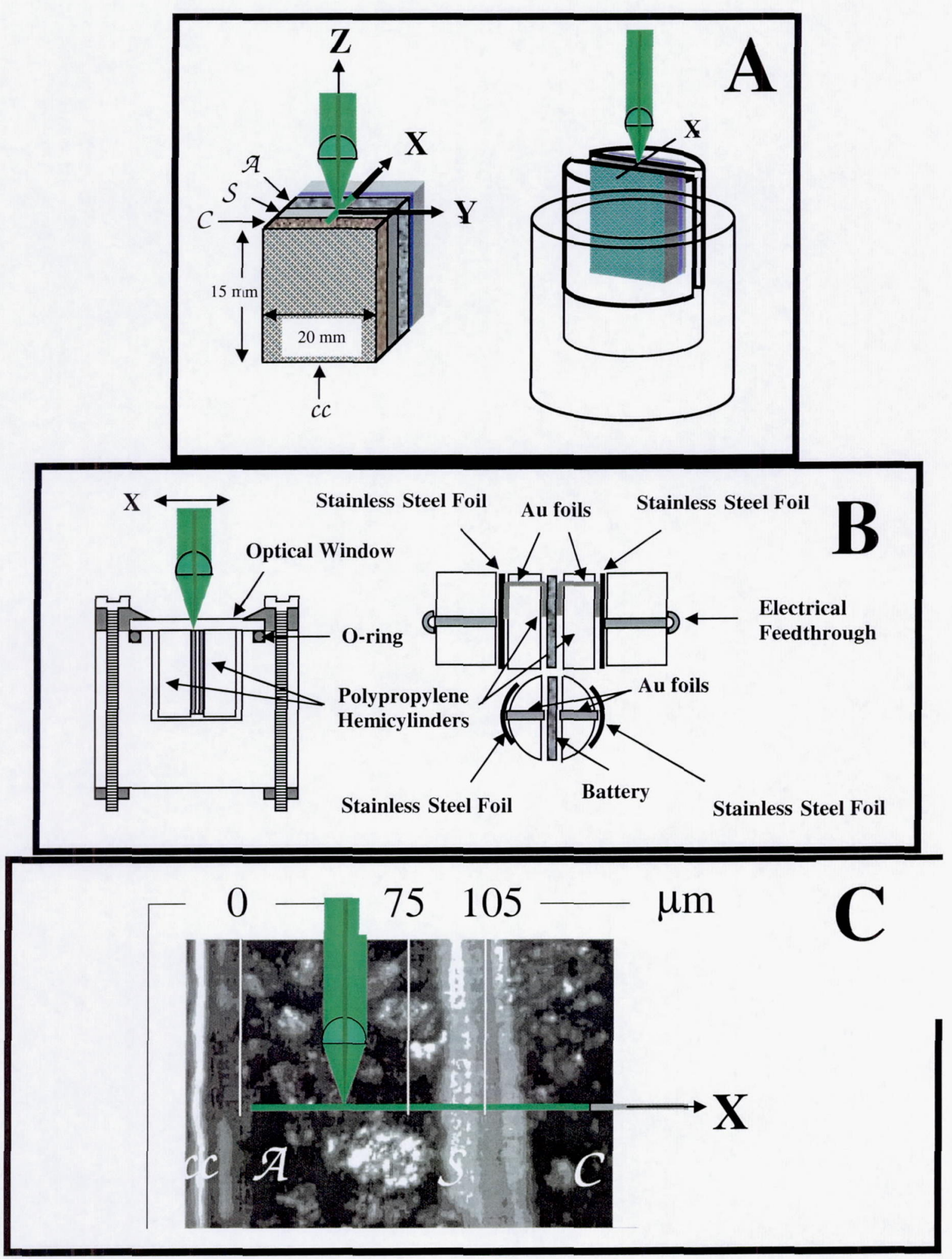

Fig. 1. Schematic diagrams of the battery (Panel A) and spectroelectrochemical cell (Panel B), and microscopic image of a sharp edge of the battery showing the carbon anode $(\mathcal{A}, 120 \sim 140 \mu \mathrm{m}$ thick), the separator $(\mathcal{S}, 32 \sim 34 \mu \mathrm{m})$, and the $\mathrm{LiCoO}_{2}$ cathode $(C,>300 \mu \mathrm{m}$ thick) and the current collectors meshes $(c c)$, i.e. copper (for $\mathfrak{A}$ ) and aluminum (for $\mathcal{C}$, not shown) (Panel C). Raman spectra were collected along the $\mathrm{x}$-axis in the direction indicated. 


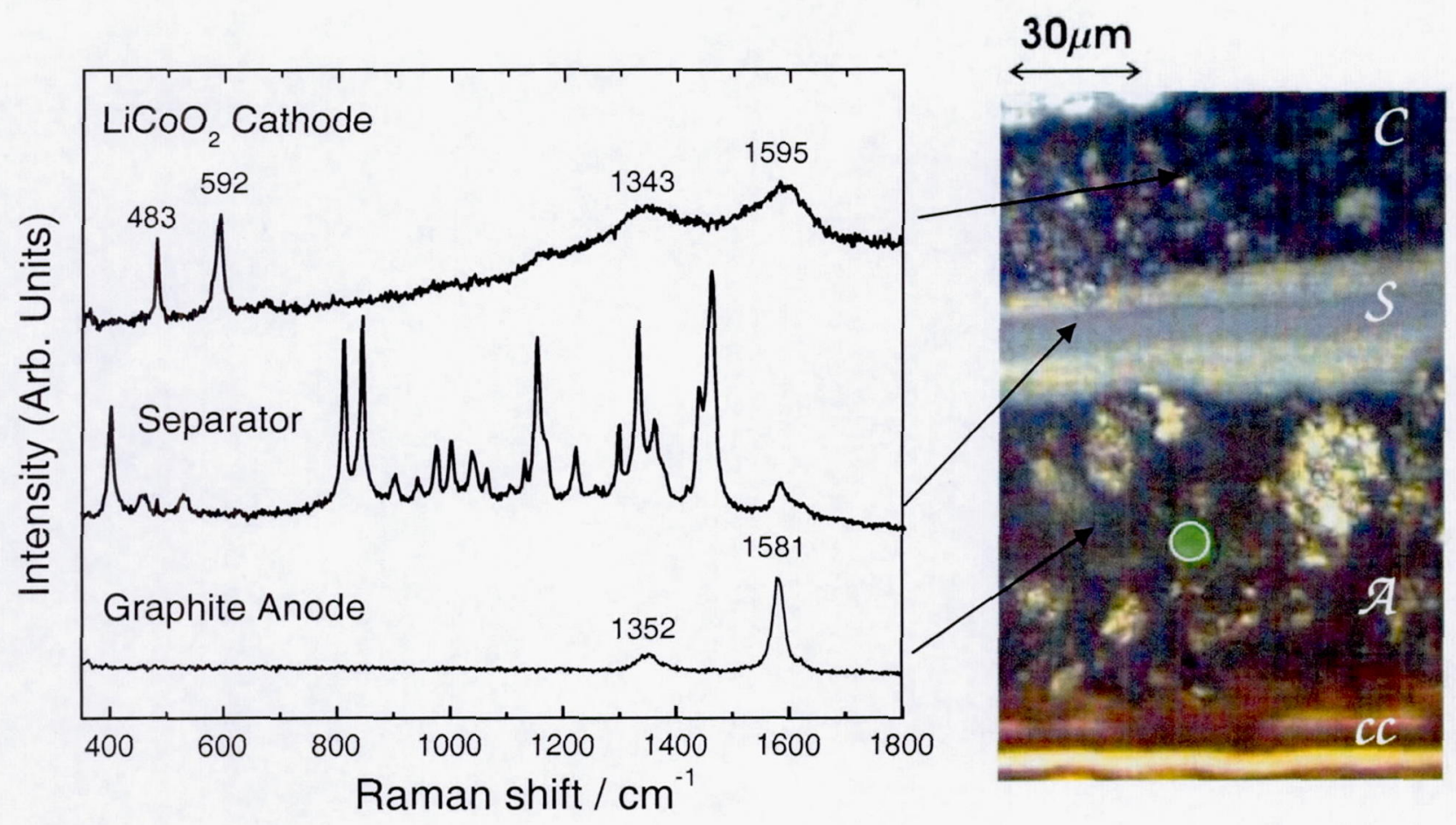

Fig. 2. Right Panel. Image obtained with the microscope attachment of the Raman 2000 showing the layered structure of the Li-ion battery. Left Panel: Raman spectra of random regions of the cathode $C$, separator, $\mathcal{S}$, and anode, $\mathcal{A}$. Laser excitation wavelength: $532 \mathrm{~nm}$. The grey circle in the picture represents the laser beam image on the battery. 

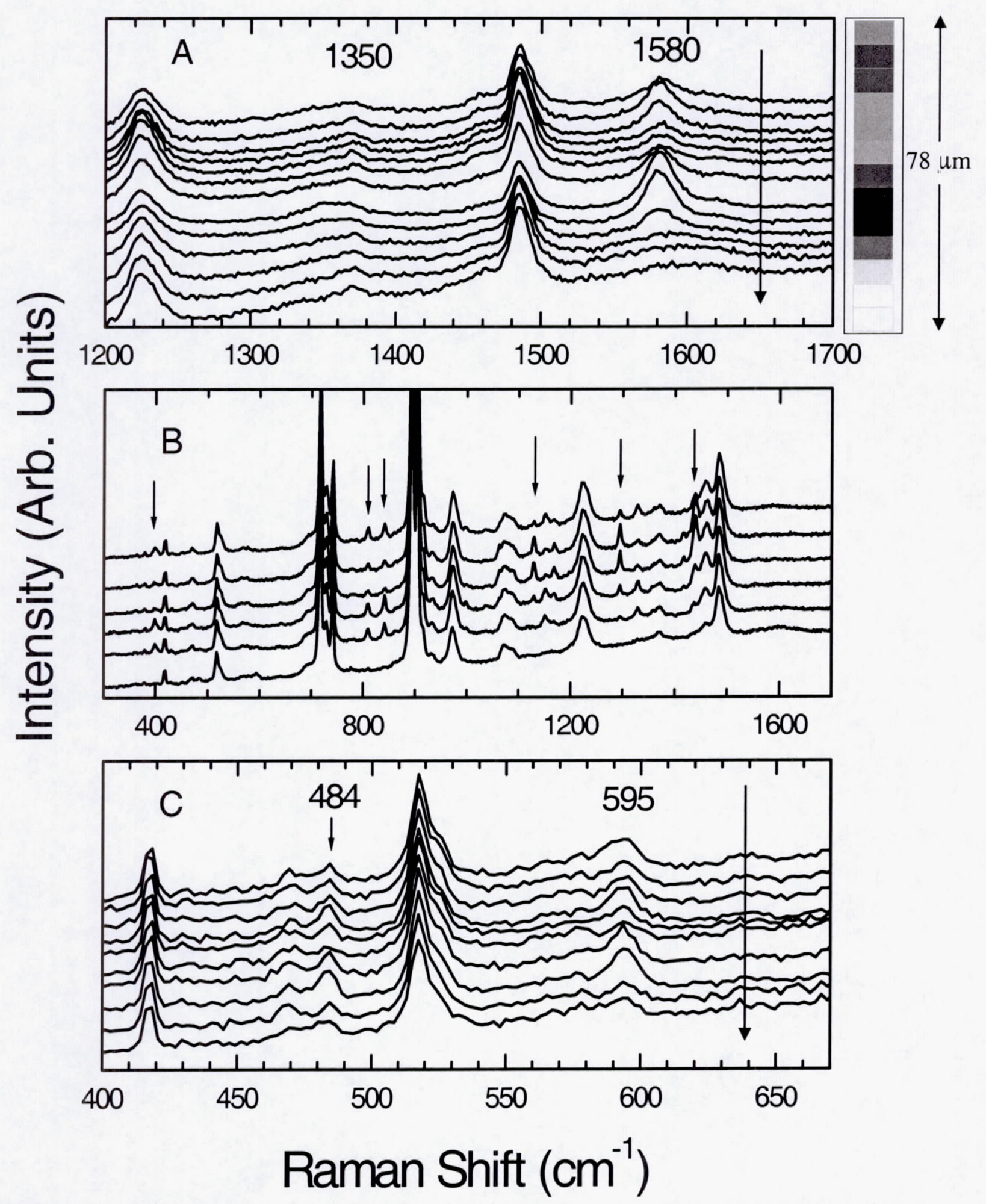

Fig. 3. Series of 30 spatially-averaged $(6 \mu \mathrm{m})$ in situ Raman spectra collected in sequence along the $\mathrm{x}$ axis close to the center of the battery (see Panel C, Fig. 1) within the anode (Panel A, ca. 78 $\mu \mathrm{m}$ ) separator (Panel B, ca. $30 \mu \mathrm{m}$ ) and cathode regions (Panel C, ca. $42 \mu \mathrm{m}$ ) for the battery in the fully discharged state. The arrow in Panel A points toward separator whereas that in Panel $\mathrm{C}$ points away from the separator. 


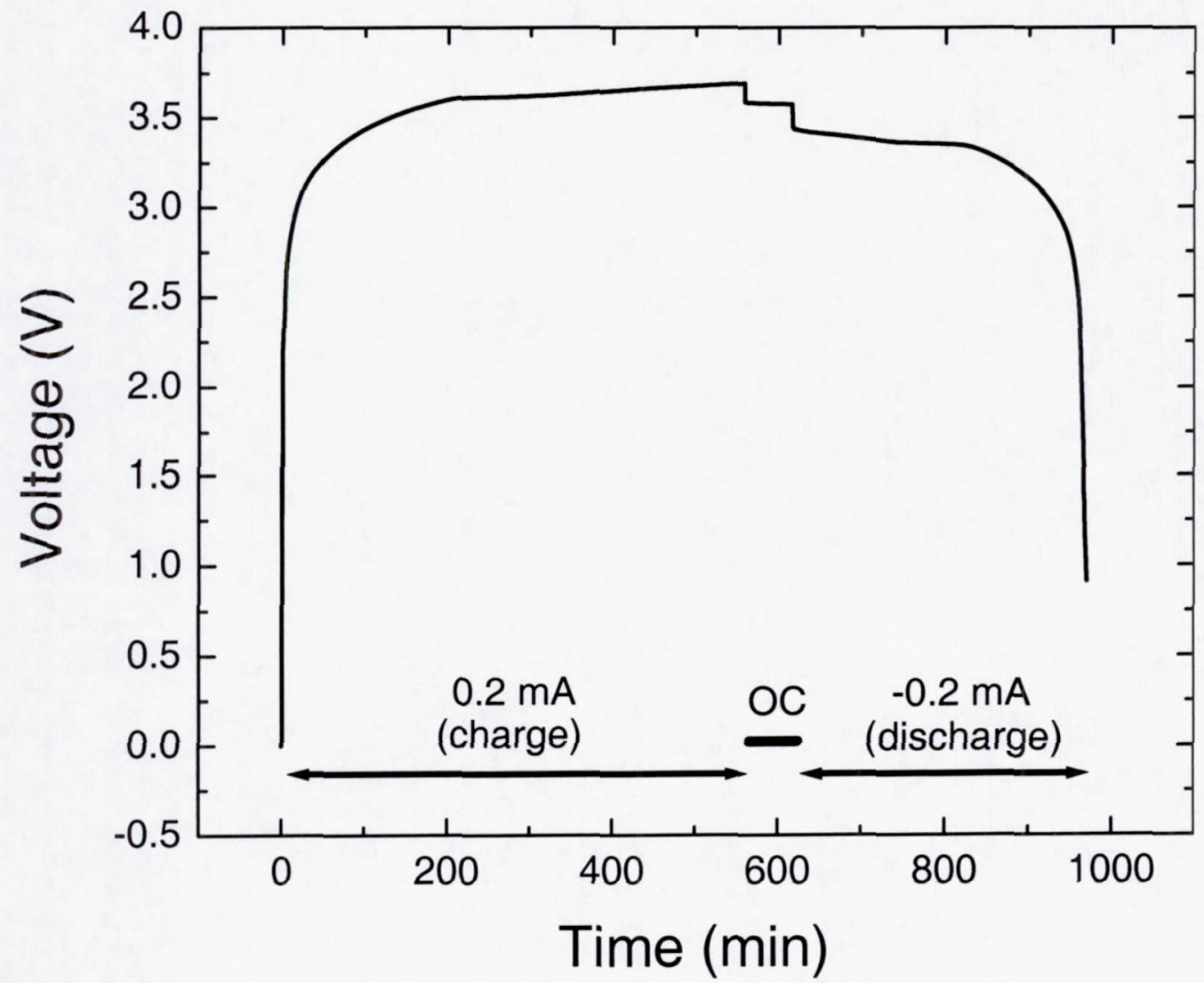

Fig. 4. Voltage vs time profile recorded during galvanostatic charge and discharge of the lithium battery at a constant current of $+0.2 \mathrm{~mA}$ and $-0.2 \mathrm{~mA}$, respectively (allowing the battery to relax (OC) for about one hour in between), while acquiring time-, and spatially-resolved Raman spectra as specified in the text. 

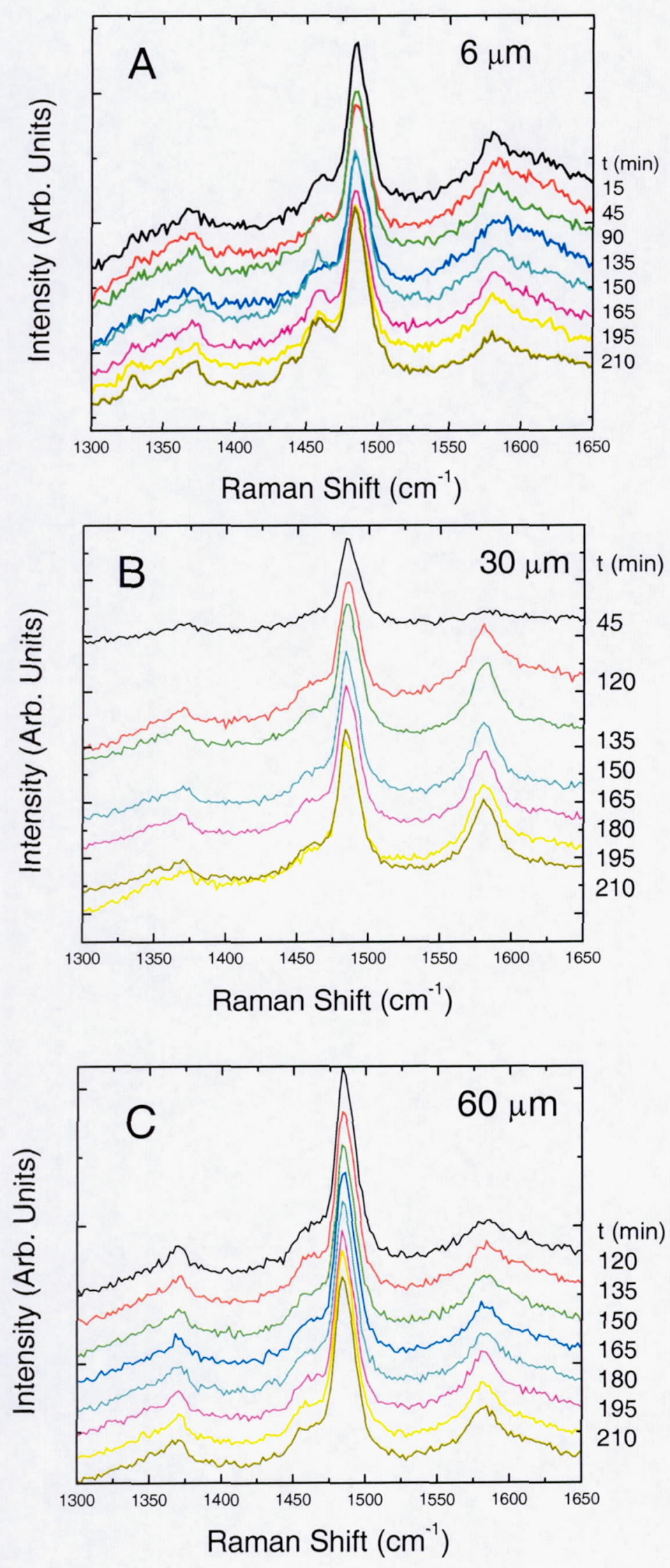

Fig. 5. Series of Raman spectra taken from the same spot on the anode during battery discharge at 6 (Panel A), 30 (Panel B) and $60 \mu \mathrm{m}$ (Panel C) from the separator as a function of time (see values next to the right axis). 

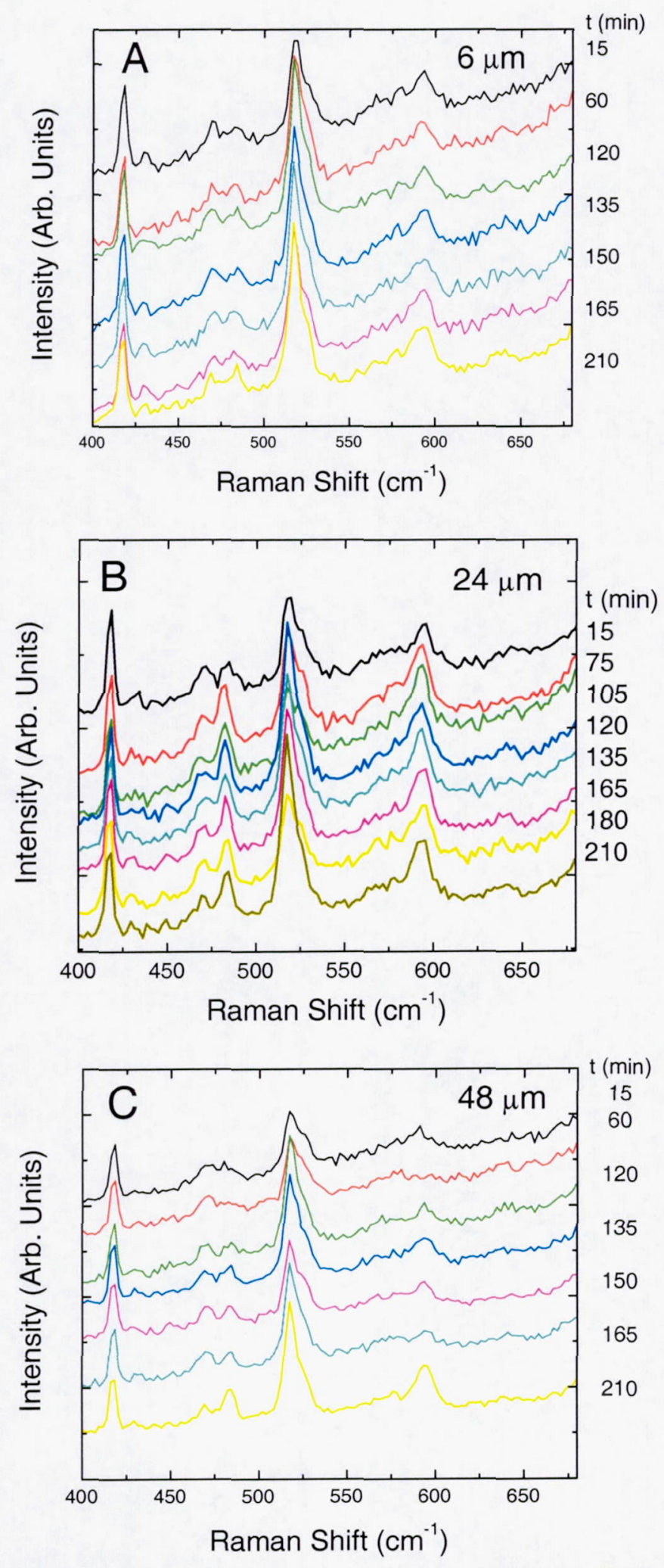

Fig. 6. Series of Raman spectra taken from the same spot on the cathode during battery discharge at 6 (Panel A), 24 (Panel B) and $48 \mu \mathrm{m}$ (Panel C) from the separator as a function of time (see values next to the right axis). 


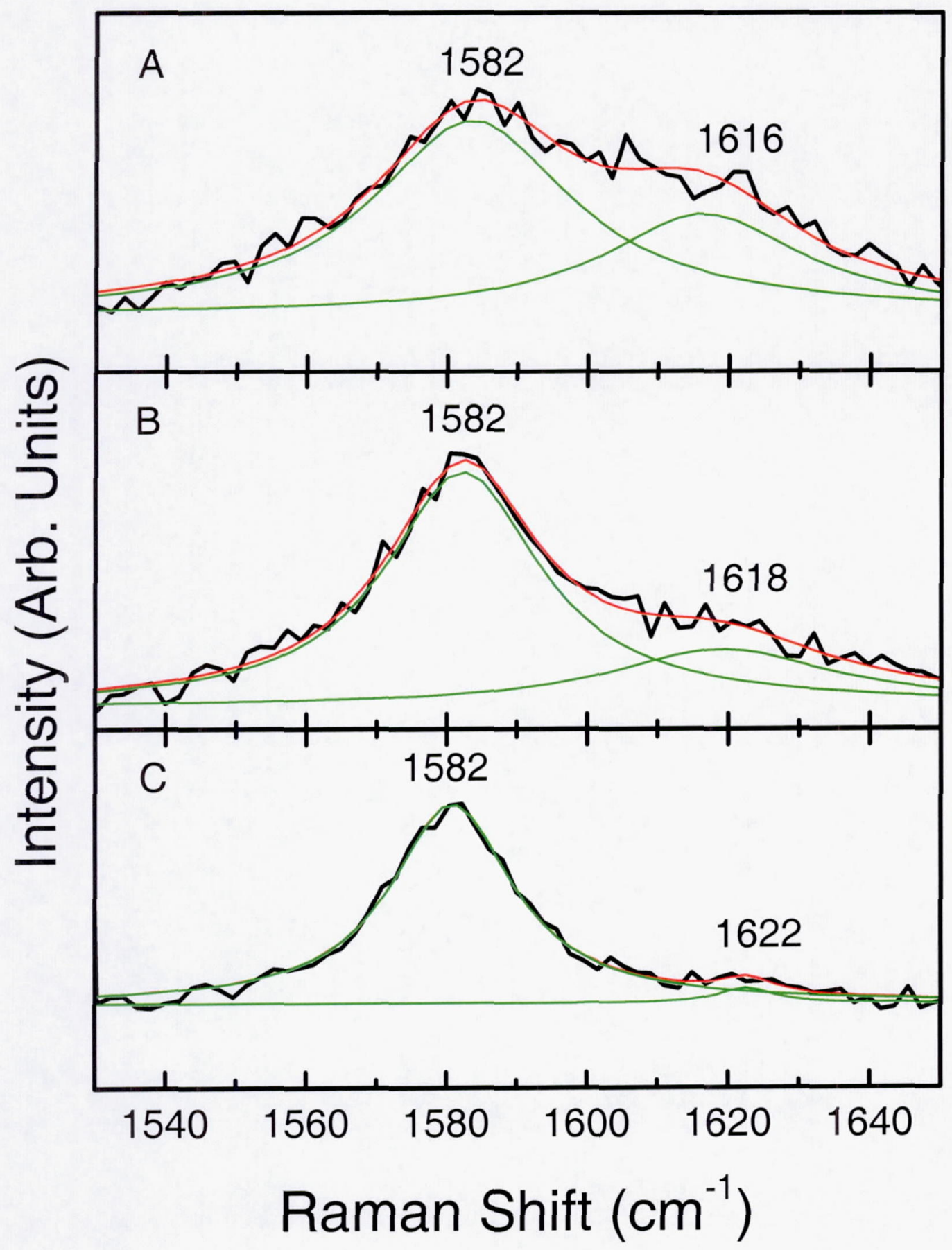

Fig. 7. Statistical fits in terms of two Lorentzians of three Raman spectra selected from the larger set shown in Fig. 5, namely, $\mathrm{t}=45 \mathrm{~min}$ and $\mathrm{x}=60 \mu \mathrm{m}$ (Panel A); $\mathrm{t}=196 \min$ and $\mathrm{x}=6 \mu \mathrm{m}$ (Panel B), and $\mathrm{t}$ $=180 \mathrm{~min}$ and $\mathrm{x}=30 \mu \mathrm{m}$ (Panel C). 


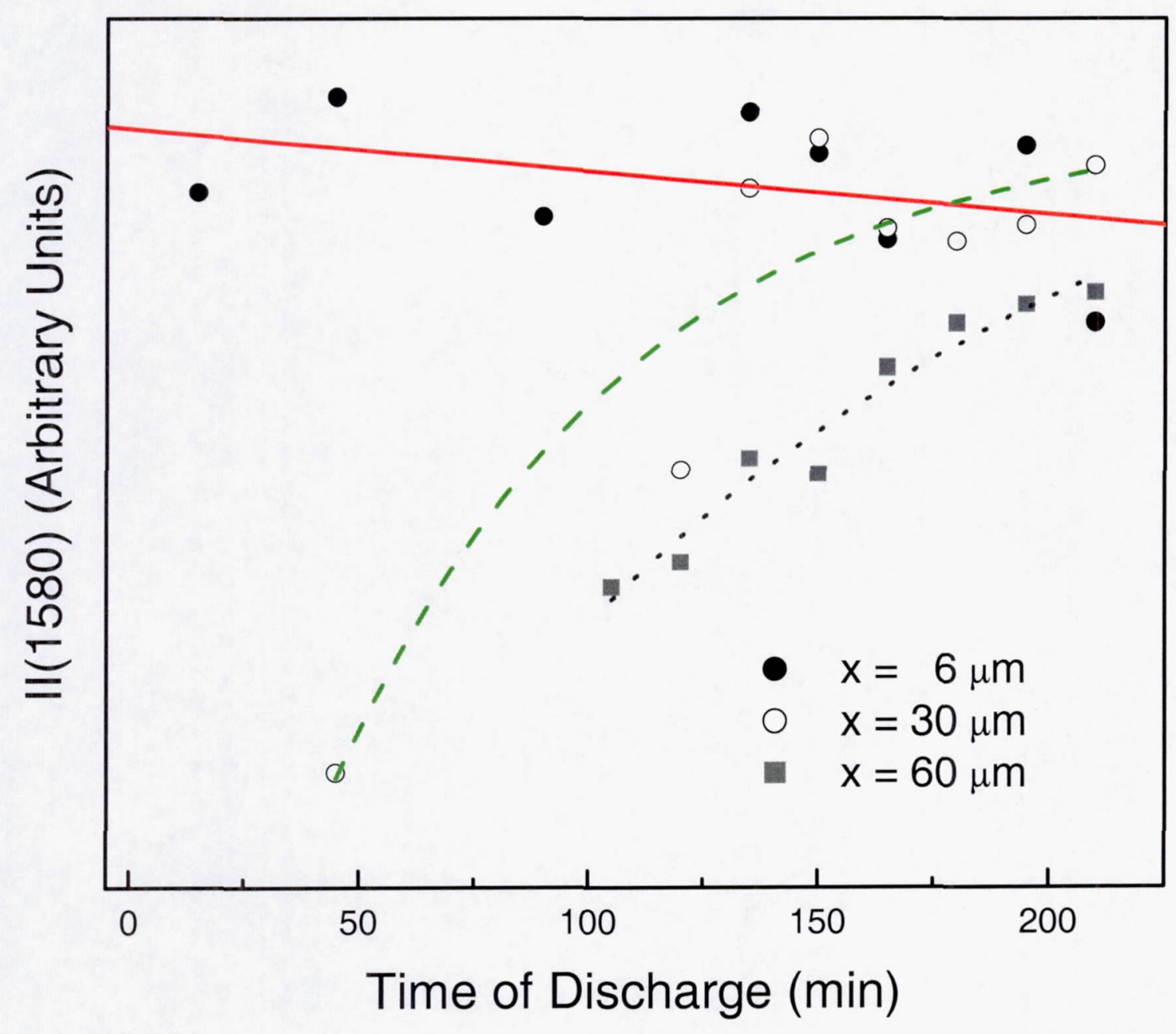

Fig. 8. Plots of the integrated intensity of the graphite band at $1580 \mathrm{~cm}^{-1}, \mathrm{II}(1580)$, for the anode region along the battery edge as a function of time during galvanostatic discharge (see Fig. 4) at specific points $x$ from the separator. Values of II(1580) were derived from the statistical analysis of the data shown in Fig. 5. The lines in this figure represent arbitrary fits to the data. 